\title{
Transforming Science Education through Digital Technology
}

\author{
Farkhunda Rasheed Ch. ${ }^{1}$, Sidra Khushnood ${ }^{2}$
}

\begin{abstract}
Science teaching and learning has always been the attention of the researchers. Learning science became significant through experiential integrations. The learning experiences for science education can become rich if virtual reality (VR) technology is infused with learning. The purpose of the study was to measure the improvement in scores and interest of the learners towards science using VR science videos. The sample consisted of 80 students of which 40 students were in control group in which 20 students were $4^{\text {th }}$ graders and 20 students were from $7^{\text {th }}$ graders. The other 40 studnets were in experimental group in which 20 students were $4^{\text {th }}$ graders and 20 students were $7^{\text {th }}$ graders. Questionnaire was administered to measure the interest of the learners. A pretest-posttest experimental research design was used. The interest questionnaire along with pretest was administered before VR intervention and a posttest along with interest questionnaire was administered after VR intervention. The results reflected the positive impact of the treatment. The results showed students' improved scores and interest towards science for $4^{\text {th }}$ as well as $7^{\text {th }}$ graders. It is recommended to use VR for the teaching and learning of science concepts to make positive students' interest towards science.
\end{abstract}

Keywords: Virtual Reality, Visualization, Imagination, Science Education

\section{Introduction}

There are many genres of digital technology but "Virtual Reality" technology is a newly emerging technology in the context of science education which is particularly characterized by high degrees of "immersion" and "interaction" with making the learner "engaged" by physically present in the non-physical world (Freina \& Ott, 2015). Now-a-days in the developed countries, there is provision of entire virtual reality learning environment (VRLE) simulating the real situation and providing "imagination" of the learners' by "visualizing" the possibilities through computer interface. Learners can get "more engaged" and interlock into real-time learning experience provided by

\footnotetext{
${ }^{1}$ Assistant Professor, Science Education Department, AIOU, Islamabad Email: farkhunda.rasheed@aiou.edu.pk

${ }^{2}$ M.Phil Scholar, Science Education Department, AIOU, Islamabad

Email: sidraaiou@gmail.com
} 
virtual reality digital technology. In 1960, Ivan Sutherland initially proposed the idea of virtual reality which is "to construct a synthetic environment through visualization using a head-mounted device" (Cheng \& Tsai, 2013). The "virtual reality executions usually make usage of "high speed", "high quality three dimensional graphics", three dimensional acoustic, as well as specified hardware like head-mounted displays (HMDs) also underwired outfit to attain high degrees of practicality and credibility (Fogler \& Bell, 2015). Fernandez (2017) quoted the definition of VR as "the action to induce a targeted behavior in an organism by using artificial sensory stimulation, while the organism has little or no awareness of the interference". As compared to simulation, virtual reality delivers the learner with intense feeling of "being there". Many researchers found the increased student interest and enthusiasm towards science subjects using virtual reality. Burdea et al. (2004), explained characteristics of virtual reality technology in the form of a triangle (Santos \& Junho, 2017).

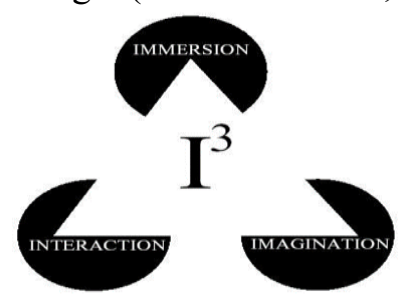

Figure 1: Virtual Reality Triangle

There are three main types of virtual reality technology. The one is nonimmersive and the other is semi-immersive and the third one is fully immersive. The non-immersive type of VR uses "desktop system" and the VR environment is watched by high resolution standard monitor but this type is the least interactive as this requires only two dimension devices such as keyboards and trackballs. The other is "semi-immersive VR" technology. It demands the "high performance graphics computer system" with "large screen monitor" along with "large screen projector system" and "multiple television projection systems". The other type is fully immersive VR which is the most interactive technology in which the learner wears the HMDs to engage in the virtual environment. With the help of VR technology, science could become much more interesting for students, better learner engagement, deliver dynamic and constructivist education, upsurge occurrence of authentic education practices; countenance for empathetic practices, empower the learners to exercise creativity, and propose a platform for visualizing many abstract theories concretely (Lee \& Hu-Au, 2017). 
Keeping the usefulness of this emerging technology, this paper address the general acceptance and explores its effects on learners' achievement. There is a research in the Pakistani set up that provides strong evidence of employing visual aids in the pedagogy as it accelerates thinking process and advances learning environment (Shabiralyani, Hasan, Hamad \& Iqbal, 2015 ) that ultimately throws positive impacts on learners' autonomic choice for technology. Technologically linked science classroom is an emerging demand of the present era because in developed countries, there is the provisions of entire virtual reality learning environment (VRLE) which can simulate the real situation and opens new horizon by providing interaction and immersion and can spark up the imagination of the learners. Therefore, it could be strong medium for educational purposes which seems to be very apt for this technical era.

There are many research studies which emphasize the use of immersive VR in teaching and learning (Fogler \& Bell, 2015; Elvestad, 2016). There are many researches about the use of VR in education that focused on K-12 (Merchant, Goetz, Cifuentes, Kennicutt, \& Davis, 2014; Black, 2017). There are few researches that discuss the VR for children (Bailey \& Bailenson, 2017; Southgate, 2018; Kim, 2007) but there are many researches that emphasize the use of VR in learning for elementary and high school students (Nadan, Alexandrov, Jamieson, \& Watson, 2011; Annetta, Mangrum, Holmes, Collazo, \& Cheng, 2009; Liou \& Chang, 2018) and higher levels. This research was done to find out the difference in academic achievement among the students of early grades and elementary grades.

\subsection{Objectives of Study}

Following are the objectives of study;

1. To measure the academic achievements of the learners while learning science through VR.

2. To find the attitude of students in science learning through VR.

\subsection{Hypotheses of Study}

Following were the hypotheses of the study;

$\mathrm{H}_{01}$ : There is no significant difference between the academic achievement of the students at pretest and posttest of grade 4 and grade 7.

$\mathrm{H}_{02}$ : There is no significant difference between the academic achievement of the students at pretest and posttest of grade 4 .

$\mathrm{H}_{03}$ : There is no significant difference between the academic achievement of the students at pretest and posttest of grade 7 .

$\mathrm{H}_{04}$ : There is no significant difference regarding interest towards science before and after the treatment of the students of grade 4 and grade 7 . 
$\mathrm{H}_{05}$ : There is no significant difference regarding interest towards science before and after the treatment at grade 4 students.

$\mathrm{H}_{06}$ : There is no significant difference regarding interest towards science before and after the treatment at grade 7 students.

\subsection{Significance of Study}

Virtual reality provides an interactive and immersive experience that can engage the learners and gradually develops interest towards science. VR links the science with technology and thus promotes STEM learning. VR technology has the potential to minimize the distraction that is present in any other digital environment of learning as VR engages the learner to visualize being actually present in the non-actual world. VR- based learning in this sense, provides concrete experience and has its roots in constructivist theory of learning where every learning comes from experience. Virtual reality technology thus providing distraction-free and fully engaged learning is very beneficial for structuring knowledge. Students get exposure to advanced technologies which encourages and supports them to cope in this technological era. Employing virtual reality in classrooms, teachers will began learning how to use the modern technologies and this would ultimately make their teaching pedagogical skills more effective and efficient.

\subsection{Delimitations of Study}

By safekeeping the time and resources, the extension of the study is restricted in many domains that can be explained as following;

1. The study was restricted to Islamabad city only.

2. The VR-based learning was organized only in the subject of science.

3. The sample of the study was the students from grade 4 and 7 and taught through a single teacher.

\section{Literature Review}

There are many researches that provides the basis for Virtual reality as an advanced educational tool (Piovesan, Passerino, \& Pereira, 2012; Christou, 2010; Merchant, Goetz, Cifuentes, Kennicutt, \& Davis, 2014). According to Shabiralyani et al. (2015), every human being has the tendency to forget but appropriate utilization of visual aids assists to more retention. As we know from Dale's cone of experience that people usually remember $50 \%$ of what they hear and see (Davis \& Summers, 2014). Therefore visual aids that also includes sound plays an essential part in knowledge retention. Shabiralyani at el. (2015) argued that VR is appropriate for learning as it provides visual assistance with distraction free preconditions and thus can be capable of tapping the interest of learners that triggers learning. 
Virtual reality provides visualization and interaction with virtual environment .VR is a powerful source that aids teaching of all fields by allowing learners to get experience the themes, concepts or situations being physically visualized before them instead of mere imagination (Christou, 2010). The constructivist approach of virtual reality is also supported by (Dalgarno \& Lee, 2010; Huang, Rauch, \& Liaw, 2010). Christou also quoted Bruner that if learners are actively engaged in mentally processing new material, they are more likely to retain it and become able to recall (Nadan, Alexandrov, Jamieson, \& Watson, 2011; Ekstrand, et al., 2018). Therefore, it ultimately leads towards better academic achievements and by increasing engagement of the learners in the presented material will also increase their interest.

Science concepts are often intangible and difficult to understand. VR provides an effective environment for teaching and learning science in the form of games and simulations (Merchant et al., 2014). Virtual reality is capable of providing an effective platform to expedite learning (Elvestad, 2016).

With the emergence of virtual reality technology, there was need of its utilization and provision for the school children. Bailey \& Bailenson (2017) emphasised the use of VR for the children because VR is capable of providing multitude of the environment necessary for experiential learning and create curiosity among children. Southgate (2018) reported that in Australian school, teachers consider VR as a learning tool for developing learners at school level. Tiala (2005) explored the level of effectiveness for VR as an instructional tool for grade $8^{\text {th }}$ students of science classes and found significant gain in scores from pretest to posttest scores. Kim (2007) studied the effects of virtual environment on $5^{\text {th }}$ graders and found that there is greater academic achievement and positive impact on their attitude towards science when they learn with 3D virtual reality teaching method. Annetta, Mangrum, Holmes, Collazo, \& Cheng (2009) also examined the learning of $5^{\text {th }}$ graders and found high student engagement while learning with virtual reality video game. There are many researches that shows the effectiveness of VR on older students such as Parong \& Mayer (2018). The learning achievements of college students was measured in biology and the results showed positive learning and increased scores. Trindade, Fiolhais, \& Almeida (2002) also observed the students of physics and chemistry at university level and the results showed better understanding of students in virtual worlds instructional methodology. Makransky, Terkildsen, \& Mayer (2017) reported more presence of students but concluded less learning gains. Liou \& Chang (2018) developed VR classroom to enhance high school stusents' learning and educational performance. Interactive VR content had been used and the learning performance was evaluated in terms of academic achievement scores. The results 
showed significantly better achievement in motivation level and increased learning outcome scores.

VR systems are emerging rapidly in educational domain. The immersive technologies may "augment" learning by enhancing interest in the "learning content" (Rupp, Kozachuk, \& Michaelis, 2016) and VR potentially creates "immersive experiences" convincing the learners to trust on the assumption that they are "physically" present in this computer-generated space. There are many researches that expose the potential impact of 'three dimensional virtual worlds' in the context of experiential 'teaching and learning' (Jarmon, Traphagan, Mayrath, \& Trivedi, 2009). Virtual reality technology bears the potential to generate a paradigm shift in the field of education as well as training but there is little experiential evidence of its educatonal value (Makransky et al., 2017). VR helps students to experience more presence but there was the evidence of less learning resulting to build less learning outcomes. However, immersiveness condition of virtual reality positively affects the engagement, enjoyment and emotional level of the learners (Makransky \& Lilleholt, 2018).

Use of fully immersive virtual reality and by VRLE (virtual reality learning environment) in the context of learning extends the role of animation and learning with multimedia (Huang, Rauch \& Liaw, 2010). Virtual reality bears the potential to improve the learning, interest and engagement of science students and also improved learning parformance and outcomes have been observed by exposing the learners to virtual reality learning experiences (Liou \& Chang, 2018). There were many contemporary research studies related to disparate educational contexts which can be reported as in the discipline of physics (Kaufmann \& Meyer, 2009), in the discipline of chemistry (Limniou, Roberts, \& Papadopoulos, 2008), in the discipline of medical and health sciences (Moro, Stromberga, \& Stirling, 2017), in the discipline of history (Black, 2017) and in the discipline of biology (Parong \& Mayer, 2018). Literature provided strong evidence of tapping learning outcomes along with motivation and unshattered engagement during learning. Therefore, virtual reality was given an acronym of RED because it was acknowledged as benefical tool for providing knowledge retention, engagement and distraction-free for science learning.

\subsection{Research Design}

\section{Research Methodology}

For the present study, pretest-posttest control group experimental research design was followed. The first phase included the data collection of individual interest of learners on science and technology through an interest questionnaire comprising of 15 statements on science and technology. After that, 
pre-test was administered on whole sample. After pre-testing, the treatment was given only on the experimental groups through VR intervention. The control groups were given ordinary learning. After giving treatment the interest questionnaire was administered again on the whole sample including control groups and experimental groups.

\subsection{Population of Study}

The focus was on fourth graders and seventh graders of the Federal Government School, Lakhwal, Islamabad. The whole population collectively for grade 4 and grade 7 was 155 which was recently registered in the government record of 2018 and was actually present there.

\subsection{Sample and Sampling Technique}

The sample consisted of 80 students of which 40 students were in control group in which 20 students were $4^{\text {th }}$ graders and 20 students were from $7^{\text {th }}$ graders. The other 40 studnets were in experimental group in which 20 students were $4^{\text {th }}$ graders and 20 students were $7^{\text {th }}$ graders.

\subsection{Instrumentation}

Questionnaire was used to measure the interest of students and a test to measure academic achievement. The instrument for measuring 'interest towards science' was initially comprised of 25 items. The content validity was ensured by the opinion of the experts. It was also piloted on a small sample. Initially this questionnaire had low reliability value. At later, some items were deleted to make it more reliable. The final instrument consisted of 15 items that has alpha reliability value of 0.733 with maximum scores of 75 . The 5-point Likert scale was used with 1 value was assigned to strongly disagree, 2 for disagree, 3 for don't know, 4 for agree and 5 value was assigned to strongly agree. The achievement test was composed of 20 items with maximum scores of 20. Its content validity was also ensured and the reliability value was 0.746 . Students were exposed to virtual reality by viewing three sixty degree immersive video seen through head-mounted display. The videos of the relevant topic were searched from YouTube and were finalized with the experts' opinion.

\subsection{Intervention}

The selected videos were downloaded before intervention to the students. There were 12 videos that were selected and pre-downloaded for intervention to the experimental groups. These videos were about the concepts regarding internal organs of human body and the solar system. The time span of these videos ranged from 5-7 minutes. The lesson plans were developed for intervention. The duration of the intervention was 4 weeks. The control groups were taught through 
lecture method. The experimental group was initially briefed about content before exposing to the intervention, moreover, briefing was also provided about the use of VR gadget. The pre-test was administered before the intervention and after that post-test was administered at the completion of intervention. The achievement test comprised up of multiple choice questions. There were 20 multiple choice questions each carried 1 score. The interest of students towards science was measured while administering the pre-test and post-test. The interest of the students was measured in the terms of usefulness, reflective, and curiosity regarding VR. The interest towards science questionnaire comprised of 75 scores in total and was based on 5-point Likert scale.

\subsection{Data Collection}

The first phase of the study involved in the data collection of the individual interest of the learners on science and technology through an interest questionnaire which was based on 5-point Likert scale. A pretest was also administered on control and experimental group. The intervention of VR-learning was administered only on experimental groups. The control groups were taught through lecture method. After administering intervention, the interest questionnaire and the posttest were administered on both groups i.e., for control groups and experimental groups. Students of the experimental group were given exposure to virtual reality through videos of science concepts by virtual reality gadget.

\subsection{Data Analysis}

For data analysis, descriptive and inferential statistics were employed Independent sample t-test and paired sample t-test were applied for drawing the inferences and test the hypotheses. 
Table 4.1

\section{Data Analysis \& Interpretation}

Overview of the achievement scores in general science for pretest and posttest

\begin{tabular}{|c|c|c|c|c|c|c|c|}
\hline Grade & Test & Group & Mean & $\overline{S D}$ & $\mathrm{df}$ & $\mathrm{t}$ & Sig. \\
\hline \multirow{6}{*}{4} & Pretest & Control & 9.35 & 0.812 & \multirow{3}{*}{38} & \multirow[b]{2}{*}{0.804} & \multirow{2}{*}{0.426} \\
\hline & & & & & & & \\
\hline & \multirow{4}{*}{ Posttest } & Experimental & 9.55 & 0.759 & & & \\
\hline & & Control & 10.02 & 0.443 & \multirow{3}{*}{38} & \multirow{3}{*}{48.433} & \multirow{3}{*}{0.000} \\
\hline & & & & & & & \\
\hline & & Experimental & 16.55 & 0.655 & & & \\
\hline \multirow[t]{5}{*}{7} & Pretest & Control & 8.20 & 1.735 & \multirow[b]{2}{*}{38} & \multirow[b]{2}{*}{1.306} & \multirow{3}{*}{0.199} \\
\hline & & & & & & & \\
\hline & \multirow{3}{*}{ Posttest } & Experimental & 7.55 & 1.39 & & & \\
\hline & & Control & 8.55 & 1.63 & \multirow[b]{2}{*}{38} & \multirow[b]{2}{*}{17.77} & \multirow[b]{2}{*}{0.000} \\
\hline & & Experimental & 15.95 & 0.887 & & & \\
\hline
\end{tabular}

Table 4.1 shows that mean scores of control groups of grade 4 and grade 7 in the pretest were not significantly higher than their respective experimental groups. However, the experimental groups of both grades i.e grade $4^{\text {th }}$ and grade $7^{\text {th }}$ were found significantly better than pretests. Therefore, the posttest shows the significant gain of academic achievement. Therefore, as the experimental group of the posttest of grade 4 and grade 7 shows significant academic achievement which reflects that the intervention has positive effects on the learners' academic performance. This indicates that $\mathrm{H}_{02}$ and $\mathrm{H}_{03}$ have been rejected.

Table 4.2

Overall difference of academic achievement scores in general science for pretest and posttest of the students

\begin{tabular}{ccccccc}
\hline Test & $\mathrm{N}$ & Mean & SD & t & df & Sig. \\
\hline Pretest & 80 & 8.72 & 1.503 & & & \\
& & & & 9.630 & 79 & 0.000 \\
Posttest & 80 & 12.76 & 3.68 & & &
\end{tabular}

Table 4.2 presents the overall difference of the academic achievement scores for the pretest and posttest of the students in general science. The overall mean scores of the pretest was 8.72 and the overall mean scores of the posttest was 12.76. The $t$-value was 9.630 which shows signifcance at $p<0.001$. It reflected that the difference of mean scores of academic achievement for the 
pretest and posttest was signifcant. The results of table 2 shows that $\mathrm{H}_{01}$ has been rejected.

Table 4.3

Overview of the difference in students' interest towards science

\begin{tabular}{|c|c|c|c|c|c|c|c|}
\hline Grade & Test & Group & Mean & SD & $\mathrm{df}$ & $\mathrm{t}$ & Sig. \\
\hline \multirow{4}{*}{4} & Pretest & Control & 3.34 & 0.272 & \multirow{3}{*}{38} & \multirow[b]{2}{*}{0.944} & \multirow[b]{2}{*}{0.351} \\
\hline & & & & & & & \\
\hline & & Experimental & 3.49 & 0.690 & & & \\
\hline & Posttest & Control & 3.66 & 0.295 & & & \\
\hline \multirow{7}{*}{7} & & & & & 38 & 12.044 & 0.000 \\
\hline & & Experimental & 4.47 & 0.055 & & & \\
\hline & Pretest & Control & 3.47 & 0.245 & \multirow[b]{2}{*}{38} & \multirow[b]{2}{*}{0.365} & \multirow{3}{*}{0.719} \\
\hline & & & & & & & \\
\hline & \multirow{3}{*}{ Posttest } & Experimental & 3.52 & 0.519 & & & \\
\hline & & Control & 3.33 & 0.346 & \multirow[b]{2}{*}{38} & \multirow[b]{2}{*}{10.171} & \multirow[b]{2}{*}{0.000} \\
\hline & & Experimental & 4.16 & 0.119 & & & \\
\hline
\end{tabular}

Table 4.3 represents the overall view of the difference of interest towards science at the time of pretest and posttest of the learners. The mean score of control group and experiment groups of both grades regarding interest towards science was less at the time of pretest than posttest. The interest towards science and technology was found better at the time of than posttest. It reflects the positive change in interest of learners by use of virtual reality technology. The results of the table 3 show that $\mathrm{H}_{05}$ and $\mathrm{H}_{06}$ have been rejected.

Table 4.4

Overall difference of students' interest towards science in general science at the time of pretest and posttest

\begin{tabular}{ccccccc}
\hline Test & $\mathrm{N}$ & Mean & SD & t & df & Sig. \\
\hline Pretest & 80 & 3.45 & 0.466 & & & \\
& & & & 6.474 & 79 & 0.000 \\
Posttest & 80 & 3.90 & 0.500 & & & \\
\hline
\end{tabular}

Table 4.4 represents the overall difference of the interest of students towards science at the time of pretest and posttest of the students in general science. The overall mean scores of the pretest was 3.45 and the overall mean scores of the posttest was 3.90. The t-value was 6.474 which shows signifcance at $\mathrm{p}<0.001$. It represents that students develop their interest towards science and virtual reality technology. It also indicated that $\mathrm{H}_{04}$ has been rejected. 


\section{Discussion}

Experimental groups showed better performance in science than that of control groups whereas the experimental groups received the treatment which was given through virtual reality gadgets. It was found that the achievement in general science resulted due to intervention. There was significant difference between the mean scores of academic achevement in posttest of experimental group. The scores of experimental group regarding interest towards science using virtual reality in posttest was high as compared to control group. The experimental groups showed significant difference of academic achievement in the posttest. The experimental group showed improved interest towards science in the posttest due to use of virtual reality. In the light of literature the results are inline with Elvestad (2016), Merchant et al. (2014) and Rupp et al. (2016) but the results of the study were contrary to Makransky, Terkildsen \& Mayer (2017). The findings showed that there exists a marked difference of achievement scores of experimental group which received treatment through virtual reality. The fndings also showed that the interest or attitude of the students developed and increased to learn general science when the learners were exposed to scientific concepts by using virtual reality gadget. It was found that the provision of VR had positive impact on the interest and academic achievements of students of both grades. This finding is in line with the studies of Kim (2007), Bailey \& Bailenson (2017) which found VR to be effective for early graders. The findings are also in line with the study of Tiala $(2005)$ which focused on grade $8^{\text {th }}$ students. However, there are studies, which supports that older students get better results when taught through VR. Technology plays significant role for developing interest that positively affects the achievement level. In developed countries, technology embeded instructions are being provided in classrooms, therefore, this study also explored its impact in our classrooms. It is the dire need to make provision for virtual reality technology in our science curriculum and teaching methodologies. The function of VR is to make learning easier by provding visualization and improving student's clarity for science concepts.

\section{Conclusion}

On the basis of above fndings, it is concluded that there is significant difference between the outcomes of virtual reality based teaching and learning practices than ordinary practices. Virtual reality based teaching and learning for general science may be adopted because it has significantly positive effects on the understanding of learners which is reflected in the form of improved results. Virtual reality based learning also increases the interest of the learners as learners 
get better clarity of scientifc concepts. It is concluded that virtual reality technology helps in devolping visualization ability among students which also develops more interest among students towards science.

\section{Recommendations}

1. This research presented the limited view of the usefulness of the virtual reality technology in science education context. It may supplements little to the small research baseline but upcoming research should employ other forms of research work with different population and with diversified instrumentation regarding virtual reality for providing more contexualize and authentic learning experiences.

2. This study can be replicated to other educational disciplines. It is recommended that the future research should explore the sources for implementing virtual reality in the real classroom setting.

3. It is recommended that virtual reality technology should employ in teaching of general science to enhance the interest of students towards science subjects for more engaged learning. Since it is a new concept, therfore, teachers should be trained for the use of latest technologies for teaching learning science process so that more clarity of concepts, retention,interest and engagement can be made possible.

\section{References}

Annetta, L., Mangrum, J., Holmes, S., Collazo, K., \& Cheng, M.-T. (2009). Bridging Reality to VR: Investigating gender effect and student engagement on learning through video game play in an elementary school classroom. International Journal of Science Education, 31(8), 1091-1113.

Bailey, J. O., \& Bailenson, J. N. (2017). Considering Virtual Reality In Children's Lives. Journal of Children and Media, 11(1), 107-113.

Black, E. R. (2017). Learning then and there: an exploration of virtual reality in k-12 history education (Plan-II Honors Thesis), University of Texas, Austin.

Cheng, K.-H., \& Tsai, C.-C. (2013). Affordances of Augmented Reality in Science Learning: Suggestions for future Research. Journal of Science Education and Technology, 22(4), 449-462. 
Christou, C. (2010). Virtual Reality in Education. In Tzanavari, A., Tsapatsoulis, N., (Eds.), Affective, Interactive and Cognitive Methods for E-Learning Design: Creating an Optimal Education Experience, (pp 228-243).IGI Global.

Dalgarno, B., \& Lee, M. J. (2010). What are the learning affordances of 3-D virtual environments? (B. Journal compilation, Ed.) British Journal of Educational Technology, 41(1), 10-32.

Davis, B., \& Summers, M. (2014). Applying Dale's Cone of Experience to increase learning and retention: A study of student learning in a foundational leadership course. QScience Proceedings (Engineering Leaders Conference), Purdue University, West Lafayette, USA. Retrieved August 04, 2018, from http://www.qscience.com/doi/pdf/10.5339/qproc.2015.elc2014.6

Ekstrand, C., Jamal, A., Nguyen, R., Kudryk, A., Mann, J., \& Mendez, I. (2018). Immersive and interactive virtual reality to improve learning and retention of neuroanatomy in medical students: a randomized controlled study. CMAJ Open, 6(1), 103-109.

Elvestad, E. O. (2016). Evidence of Learning in Virtual Reality. Norwegian University of Science and Technology, Department of Computer Science, Norway.

Fernandez, M. (2017). Augmented Virtual Reality: How to Improve Education Systems. Higher Learning Research Communications, 7(1), 1-15.

Fogler, H. S., \& Bell, T. J. (2015). The Investigation and Application of Virtual Reality as an Educational Tool. Proceedings of the American Society for Engineering Education 1995 Annual Conference, Session number 2513, 3.

Freina, L., \& Ott, M. (2015). A Literature Review on Immersive Virtual Reality in Education: State Of The Art and Perspectives. Learning and Software for Education, 1, 133-141. 
Huang, H.-M., Rauch, U., \& Liaw, S.-S. (2010). Investigating learners' attitudes toward virtual reality learning environments: Based on a constructivist approach. Computers \& Education, 55(3), 1171-1182.

Jarmon, L., Traphagan, T., Mayrath, M., \& Trivedi, A. (2009). Virtual world teaching, experiential learning, and assessment: An interdisciplinary communication course in Second Life. Computers \& Education, 53, 169-182.

Kaufmann, H., \& Meyer, B. (2009). Physics Education in Virtual Reality: An Example. Themes in science and technology education (Special Issue), $117-130$.

Kim, P. (2007). Effects of 3D virtual reality of plate tectonics on fifth grade students' achievement and attitude toward science. Interactive Learning Environments, 14(1), 25-34.

Lee, J., \& Hu-Au, E. (2017). Virtual reality in education: a tool for learning in the experience age. International Journal of Innovation in Education, 4(4), 215-226.

Limniou, M., Roberts, D., \& Papadopoulos, N. (2008). Full immersive virtual environment CAVE in Chemistry Education. (Elsevier, Ed.) Computers \& Education, 51, 584-593.

Liou, W.-K., \& Chang, C.-Y. (2018). Virtual reality classroom applied to science education. $23^{\text {rd }}$ International Scientific-Professional Conference on Information Technology (IT) (pp. 1-4). Zabljak: IEEE Xplore.

Makransky, G., \& Lilleholt, L. (2018). A structural equation modeling investigation of the emotional value of immersive virtual reality in education. Education,Technology, Research and Development, 66(5), 1141-1164.

Makransky, G., Terkildsen, T. S., \& Mayer, R. E. (2017). Adding immersive virtual reality to a science lab simulation causes more presence but less learnng. Learning and Instruction, 60(1), 225-236.

Merchant, Z., Goetz, E., Cifuentes, L., Kennicutt, W., \& Davis, T. (2014). Effectiveness of VR-based instruction on Students' Learning outcomes in 
K-12 and Higher Education:A meta-analysis. Computers \& Education, $70,29-40$.

Moro, C., Stromberga, Z., \& Stirling, A. (2017). Vrtualizaton devices for student learning: Comparison between desktop-based (Oculus Rift) and mobilebased (Gear VR) virtual realty in medical and health science education. Australasian Journal of Educational Technology, 33(6), 1-10.

Nadan, Alexandrov, V., Jamieson, R., \& Watson. (2011). Is VR a memorable experience in an educatonal context? International Journal of Emerging Technologies in learning (IJET), 6(1), 53-57.

Parong, J., \& Mayer, R. E. (2018). Learning Science in Immersive Virtual Reality. Journal of Educational Psychology, 110(6), 785-797.

Piovesan, S. D., Passerino, L. M., \& Pereira, A. S. (2012). Virtual reality as a tool in the education. IADIS International Conference on Cognition and Exploratory Learning in Digital age, 295-298. Retrieved January 10, 2019, from https://files.eric.ed.gov/fulltext/ED542830.pdf

Rupp, M. A., Kozachuk, J., \& Michaelis, J. R. (2016). The Effects of Immersiveness and Future VR expectations on subjective experiences during an educational 360 degree video. Proceedings of the Human Factors and Ergonomics Society Annual Meeting, 60(1), 2108-2112.

Santos, B. S., \& Junho. (2017). An Introduction to Virtual (and other) Realities. ieeta, 87. Retrieved July 26, 2018, from http://sweet.ua.pt/bss/apresenta\%C3\%A7\%C3\%B5es/An\%20introductio n\%20to\%20VAR-IADE-.pdf

Shabiralyani, G., Hasan, K. S., Hamad, N., \& Iqbal, N. ( 2015 ). Impact of Visual Aids in Enhancing the Learning Process Case . Journal of Education and Practice , 6(19), 226-234.

Southgate, E. (2018). Immersive virtual reality, children and school education: A literature review for teachers. DICE Research, DICE report series Number 6. Australia: Newcastle. Retrieved November 03, 2019, from http://dice.newcastle.edu.au/DRS_6_2018.pdf 
Tiala, S. K. (2005). Virtual reality in the $k-12$ classroom (PhD Dissertation). Iowa Sate University, Iowa.

Trindade, J., Fiolhais, C., \& Almeida, L. (2002). Science learning in virtual environments: a descriptive study. British Journal of Educational Technology, 33(4), 471-488. doi: 10.1111/1467-8535.00283

\section{Citation of this Article:}

Chaudhary, F. R., \& Khushnood, S. (2019). Transforming Science Education through Digital Technology. International Journal of Innovation in Teaching and Learning (IJITL), 5(2), 17-32. 